\title{
Current Status and Recent Research Achievements in SiC/SiC Composites
}

\begin{tabular}{|c|l|}
\hline Submitted to: & Journal of Nuclear Materials (for ICFRM-16) \\
\hline Date initially submitted: & November 14, 2013 \\
\hline Corresponding author: & $\begin{array}{l}\text { Dr. Yutai Katoh } \\
\text { Oak Ridge National Laboratory } \\
\text { P.O.Box 2008, Oak Ridge, TN 37831-6138, USA } \\
\text { E-mail: katohy@ornl.gov } \\
\text { Phone: +1 (865) 576-5996 }\end{array}$ \\
\hline Complete list of authors: & $\begin{array}{l}\text { Yutai Katoh, Oak Ridge National Laboratory, USA } \\
\text { L.L. Snead, Oak Ridge National Laboratory, USA } \\
\text { C.H. Henager, Jr., Pacific Northwest National Laboratory, USA } \\
\text { T. Hinoki, Kyoto University, Japan } \\
\text { A. Iveković, Jožef Stefan Institute, Slovenia } \\
\text { S. Novak, Jožef Stefan Institute, Slovenia } \\
\text { S.M. Gonzalez de Vicente, EFDA Garching, Germany }\end{array}$ \\
\hline Silicon carbide, SiC/SiC composite, fusion materials \\
\hline
\end{tabular}

Significance of the work:

This invited paper summarizes contents of the invited plenary talk of the same title to be presented at the $16^{\text {th }}$ International Conference on Fusion Reactor Materials, October 20-25, 2013, in Beijing, China. 


\title{
CURRENT STATUS AND RECENT RESEARCH ACHIEVEMENTS IN SiC/SiC COMPOSITES
}

\author{
Y. Katoh ${ }^{1,}{ }^{*}$, L.L. Snead ${ }^{1}$, C.H. Henager, Jr. ${ }^{2}$, T. Nozawa ${ }^{3}$, T. Hinoki ${ }^{4}$, A. Iveković ${ }^{5}$, \\ S. Novak ${ }^{5}$, S.M. Gonzalez de Vicente ${ }^{6}$
}

${ }^{1}$ Oak Ridge National Laboratory, Oak Ridge, Tennessee, USA, ${ }^{2}$ Pacific Northwest National Laboratory, Richland, Washington, USA, ${ }^{3}$ Japan Atomic Energy Agency, Rokkasho, Aomori, Japan, ${ }^{4}$ Institute of Advanced Energy, Kyoto University, Kyoto, Japan, ${ }^{5}$ Jožef Stefan Institute, Ljubljana, Slovenia, ${ }^{6}$ EFDA Garching, Germany

\author{
*Corresponding author \\ Materials Science and Technology Division \\ Oak Ridge National Laboratory \\ P.O.Box 2008, Oak Ridge, TN 37831-6138, USA \\ E-mail: katohy@ornl.gov \\ Phone: +1 (865) 576-5996
}

\begin{abstract}
The development and maturation of the silicon carbide fiber-reinforced silicon carbide matrix ( $\mathrm{SiC} / \mathrm{SiC}$ ) composite system for fusion applications has seen the evolution from fundamental development and understanding of the material system and its behavior in a hostile irradiation environment to the current effort which essentially is a broad-based program of technology, directed at moving this material class from a laboratory curiosity to an engineering material. This paper lays out the recent international scientific and technological achievements in the development of $\mathrm{SiC} / \mathrm{SiC}$ composite material technologies for fusion application and will discuss future research directions. It also reviews the materials system in the larger context of progress to maturity as an engineering material for both the larger nuclear community and for general engineering applications.
\end{abstract}




\section{Introduction}

Since the early development effort for tri-layered isotropic (TRISO) micro-encapsulated fuels in 1960's for the high temperature gas-cooled reactors [1], silicon carbide (SiC) has been studied as the refractory nuclear material, eventually proving its outstanding high temperature strength, creep resistance [2], oxidation resistance [3], and radiation tolerance [4, 5]. Shortly after the epochal invention of the continuous SiC-based fiber by Yajima et al in mid-1970's at the nuclear materials laboratory of Tohoku University [6], the race for development of ceramic fiberreinforced ceramic matrix composites (CMC) started to yield various kinds of continuous SiC fiber-reinforced SiC-matrix ( $\mathrm{SiC} / \mathrm{SiC}$ ) structural composites, including those through the chemical vapor infiltration (CVI) [7], liquid silicon infiltration (LSI) or melt infiltration (MI) [8], polymer impregnation and pyrolysis (PIP) [9], and transient eutectic phase (TEP) [10] processes.

The CMC's distinguish themselves from the monolithic ceramics for several outstanding features including the damage tolerance, highly predictable failure properties, and the ability of near-net shaping for complex geometries. The application of SiC-matrix composites to fusion reactor blankets was proposed in late 1970's by Riley, et al.[11] The exceptional low activation / low decay heat properties [12] and the lesser impact on the tritium breeding were among the additional factors that $\mathrm{SiC} / \mathrm{SiC}$ composite may benefit the fusion reactors as a blanket material. However, because of the radiation-instability for the early high oxygen amorphous SiC-based fibers and the second generation carbon-rich, nano-crystalline SiC-based fibers [13, 14], demonstration of the radiation-tolerant $\mathrm{SiC} / \mathrm{SiC}$ composite had to wait until 1999 when the US Japan fusion materials collaboration project fabricated the third generation near-stoichiometric SiC fiber, CVI SiC matrix composite tested it following neutron irradiation in the High Flux Isotope Reactor (HFIR) [15]. 
Succeeding works collectively demonstrated the general radiation tolerance of the third generation SiC fiber composites through the CVI process [16] and the nano-infiltration and transient eutectic-phase (NITE) process [17] in broad ranges of irradiation temperature (300 $1300^{\circ} \mathrm{C}$ ) and neutron fluence (up to $>70 \mathrm{dpa}$ ), while the limitations in radiation resistance in certain irradiation conditions are recently being identified for particular materials [18]. While the radiation effects have been considered as the primary technical feasibility factor in the early phase of $\mathrm{SiC} / \mathrm{SiC}$ study for fusion applications, significant activities have also been undertaken in international fusion and fission materials communities toward advancing the general technological readiness levels (TRL's) $[19,20]$ for the SiC/SiC materials technologies for those applications, with the efforts ranging from understanding the fundamental radiation damage processes and the environmental effects to the component fabrication and the code qualification. The present paper summarizes the current activities, recent progress, and future opportunities in research and development of $\mathrm{SiC} / \mathrm{SiC}$ materials science and technology for fusion energy and related application areas.

\section{Synergy with non-fusion applications of ceramic matrix composites}

The successful development and demonstration of the radiation-tolerant $\mathrm{SiC} / \mathrm{SiC}$ composites in fusion materials programs attracted significant attentions in fission nuclear energy communities. Currently, the research and development of the CMC for various fission applications and the $\mathrm{SiC} / \mathrm{SiC}$ studies for fusion energy applications play significant leveraging roles with each other. 


\subsection{Advanced Fission Reactors}

The High Temperature Gas-cooled Reactor (HTGR) is the leading runner in the TRL advancement in the nuclear applications of the CMC. The use of SiC/SiC is considered necessary or highly desirable for components such as the control rod sheath that receive significant fast neutron doses at high temperatures, whereas the carbon fiber composites will serve the purposes for the structural core supports where the neutron flux is significantly more moderate $[21,22]$. The HTGR's operating at higher temperatures (Very High Temperature Reactors, VHTR's, with the helium coolant outlet temperature up to $950^{\circ} \mathrm{C}$ ) and of the prismatic cores tend to require the radiation-tolerant $\mathrm{SiC} / \mathrm{SiC}$ core components, whereas the pebble-bed core HTGR's will allow a limited use of the code-qualified high temperature alloys such as Alloy $800 \mathrm{H}$.

With the key technical feasibility issues positively addressed, $\mathrm{CMC}^{\prime}$ s are now considered the available materials technology for the HTGR applications. The current effort in US focuses on development of the design code and the standards that will be used in the qualification process for the CMC materials and components. The design rules for Composite Core Components and Composite Assemblies for High Temperature Reactors Systems are currently being developed as the American Society for Mechanical Engineers (ASME) Boiler \& Pressure Vessel Code, Section III, Division 5 - High Temperature Reactors, Subsection HH - Class A Nonmetallic Core Support Structures, Subpart B - Composite Materials, by the Sub-Group on Graphite Core Components [23]. The core components manufactured from carbon or silicon carbide fiber composites are included in the scope of the code. Moreover, in support of the ASME code development, various standard materials specifications, test methods, and test guides are being developed for the CMC's in the ASTM International's Committee C28 on Advanced Ceramics. The ASTM Standards that are currently being developed include those on specifications for 
$\mathrm{SiC} / \mathrm{SiC}$ and carbon fiber composites for nuclear applications and several test methods for mechanical properties of CMC's [24]. In addition to these ASTM Standards, the ASME design code will adopt supplemental documents such as a compilation of properties and radiation effects for the nuclear grade $\mathrm{SiC} / \mathrm{SiC}$ composites [16].

For some of the advanced reactor concepts that will demand materials more aggressive high temperature capability and radiation tolerance, $\mathrm{SiC} / \mathrm{SiC}$ composites are often the sole candidates for certain components. Such components include the fuel assemblies and core supports for the gas-cooled fast reactors (GFR's) $[25,26]$ and the fluoride salt-cooled high temperature reactors (FHR's) [27]. Moreover, the French sodium fast reactor (SFR) program considers the $\mathrm{SiC} / \mathrm{SiC}$ as the viable core material option [28].

\subsection{Accident-Tolerant LWR Cores}

The use of SiC-based materials to the light water reactor (LWR) fuel claddings had been proposed with the primary purpose of achieving a better neutronics and improved safety features [29]. After the Fukushima Dai-ichi accident in 2011, the SiC-based materials started to attract more serious considerations as the enabling materials for the Accident Tolerant Fuels (ATF) and the Accident Tolerant Core (ATC) technologies for the current fleet LWR's. The current areas of active technology development in support of the ATF/ATC programs include the $\mathrm{SiC} / \mathrm{SiC}$ composite core structures [22], the SiC/SiC composite-based fuel claddings [30], and the SiC-matrix fully ceramic micro-encapsulated (FCM) fuels [31].

Among these, the $\mathrm{SiC} / \mathrm{SiC}$ composite channel boxes for the boiling water reactors (BWR's) are at the highest TRL, with the prototype fabrication (Figure 1) and the several key evaluations including the handling accident test and thermal shock test completed. The concerns associated 
with the water corrosion, the environment-assisted slow crack growth, and the irradiation strain remain to be fully addressed.
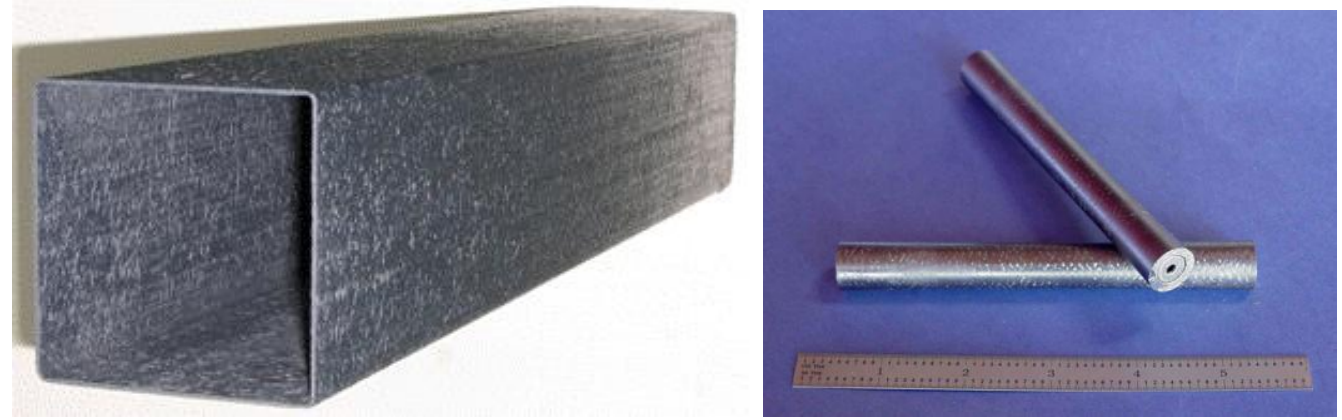

Figure 1. SiC/SiC composite components for accident-tolerant light water reactor technologies: prototypical boiling water reactor channel box (left, courtesy of Electrical Power Research Institute) and developmental small diameter tubes (right).

While the LWR fuel cladding application imposes significant more challenges to SiC/SiC composite technologies than the core structure applications, it presents interesting synergy with the fusion blanket applications. For example, the LWR fuel rods require a robust, radiationtolerant, and hermetic end-plug joining method, which will also be essential for integration of the fusion blankets. Moreover, the heat flux through the LWR fuel clad wall will exceed 0.5 $\mathrm{MW} / \mathrm{m}^{2}$ up to $\sim 1 \mathrm{MW} / \mathrm{m}^{2}$, comparable with the anticipated heat flux through the first wall of the fusion blankets. Recently, Ben-Belgacem et al [32] shown that the stress in the LWR fuel clad will be dictated by the differential swelling-induced secondary stress, transitioning from tension to compression along the heat flow, through a two-dimensional finite element analysis that takes into account the dynamic evolutions of the thermal conductivity and swelling distributions in a model $\mathrm{SiC} / \mathrm{SiC}$ clad during its service life. Combining such analyses with the 
statistical strength data for the material will enable the probabilistic failure assessment for the components.
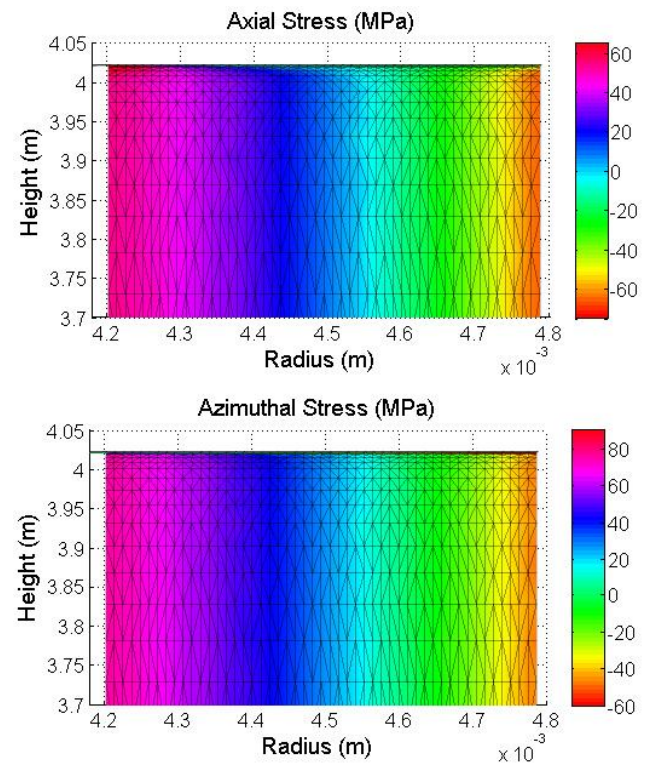

Figure 2. Dynamic finite element analysis of thermal-physical-structural evolutions in $\mathrm{SiC} / \mathrm{SiC}$ light water reactor fuel cladding, showing domination of differential swelling-induced secondary stress in the end-of-life stress state in the cladding as the result of a through-thickness temperature gradient assisted by radiation-induced thermal conductivity decrease [32].

\subsection{Non-nuclear applications}

Non-nuclear applications of the CMC's are rapidly growing where the high temperature capability beyond the metallic heat resistant alloys and the high specific strength are valued. Besides the wide-spread use of carbon/carbon composites in semiconductor industries, the leading demanding application areas for the $\mathrm{CMC}^{\prime}$ s are turbine engines for aircrafts. The use of $\mathrm{CMC}^{\prime}$ ' for the turbine engines is progress from the less-demanding exhaust components to shrouds/seals, combustors, stators/vanes, then finally rotors/blades in the order of increasing 
technical challenges. Replacing the metallic components with CMC's improve the fuel efficiency potentially very significantly through the higher temperature of combustion (that also contributes to the cleaner exhaust), reduced component weight, and the mitigated need for active cooling of the components [33]. SiC/SiC turbine shrouds are currently being tested in the CFM International's LEAP (leading edge aviation propulsion) engine, envisioning the passenger services starting in 2016. GE Aviation plans to start a large scale production of the SiC/SiC combustion liners and the turbine airfoil components for use in their next generation GE9X engines for larger passenger aircrafts. These $\mathrm{SiC} / \mathrm{SiC}$ are manufactured through the MI process, limiting the synergy with the nuclear CMC development mainly to the test methods. However, expanding synergy into areas like the design methodology and life-limiting properties is anticipated as the target application of $\mathrm{SiC} / \mathrm{SiC}$ in turbine engines progresses to more demanding components for which the further enhanced high temperature capabilities and creep resistance are required.

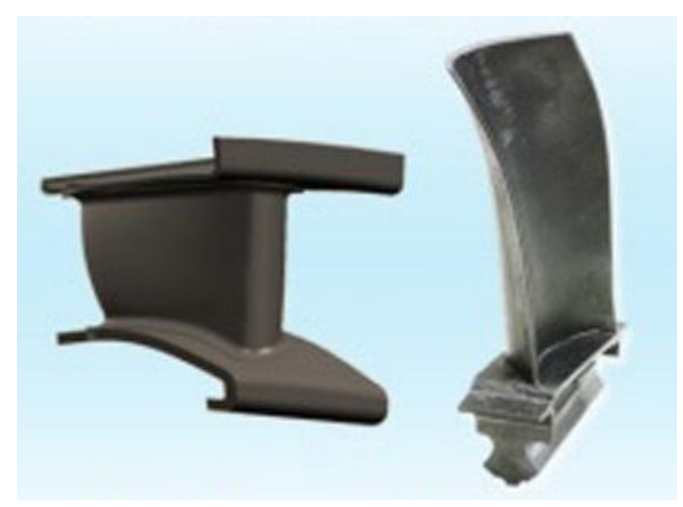

Figure 3. Prototypical SiC/SiC components for GE Aviation's next generation GE9X engine for Boeing 777X and other wide-body twin-jet passenger aircrafts (Courtesy, GE Aviation). 


\section{Requirements for fusion $\mathrm{SiC} / \mathrm{SiC}$}

The potential applications of SiC/SiC composites currently considered for the in-vessel components of the magnetic confinement fusion devices may be classified into three categories: blanket structures including the first wall (FW), flow channel inserts ( $\mathrm{FCl}$ ) for the liquid metal (LM) blankets, and the plasma-facing components (PFC's). However, there currently are no relatively mature PFC concepts that assume the use of the CMC's, despite the favorable compatibility of the tungsten - SiC system (in terms of thermal expansion, joining technology [34], and the operating temperature windows [35]) and the CMC's likely adequacy as the materials for the certain helium-cooled PFC parts and the radiatively cooled high temperature surfaces in more aggressive PFC concepts. Below, the performance requirements to the $\mathrm{SiC} / \mathrm{SiC}$ composites as the blanket structural and $\mathrm{FCl}$ materials in the recent design concepts are briefly discussed.

\subsection{Blanket structures}

The conceptual fusion power reactor blanket designs that assume the use of SiC/SiC composites as the structural and FW materials have not significantly evolved since the last review by Snead et al [36], except that the ARIES-ACT1 self-cooled lead-lithium (SCLL) blanket design [37], Figure 4, evolved from the preceding ARIES-AT concept [38]. The refinement in the newer ARIES-ACT1 design involves the slightly narrowed operating temperature window, complete removal of the gas tightness requirement for the $\mathrm{SiC} / \mathrm{SiC}$ walls, and the simplified structural design, all of which help reduce burdens to the structural material. Selected operating parameters for the SiC/SiC blanket/FW structures in some of the proposed fusion breeding blanket concepts are compared in Table 1. 
The SCLL is considered the leading concept that may use SiC/SiC as the structural material, mainly because of the relatively low coolant pressure, less demanding hermeticity requirement, and the proven static compatibility between the lead-lithium eutectic (LLE) and SiC up to very high temperatures [39]. However, the chemical compatibility in a flow condition with the temperature gradient and the fusion-relevant electromagnetic environment is yet to be clarified. The allowable stresses in some conceptual designs appear moderately challenging for the present nuclear-grade $\mathrm{SiC} / \mathrm{SiC}$, considering the long-term hermeticity requirement. The design-assumed through-thickness thermal conductivity values are slightly optimistic for the required in-plane strength, presenting the need for further design refinements and the opportunities for further materials development.

The helium-cooled ceramic breeding (HCCB) blanket also shown in Table 1 is another concept that may utilize the $\mathrm{SiC} / \mathrm{SiC}$ structures. The selection of chemically controlled helium coolant likely eliminate any serious concern for the chemical incompatibility as assessed in the HTGR and GFR studies $[40,41]$. The chemical compatibility of SiC with certain lithium oxides has been demonstrated in a high temperature, high radiation environment [42]. The helium tightness requirement under a significant stress loading due to high pressure helium containment remain a leading critical issue, for which a research synergy with the fission product gas containment in the LWR clad development is anticipated. Since the ceramic structure HCCB designs have not significantly evolved, there are significant rooms for the design refinement for this blanket concept. 

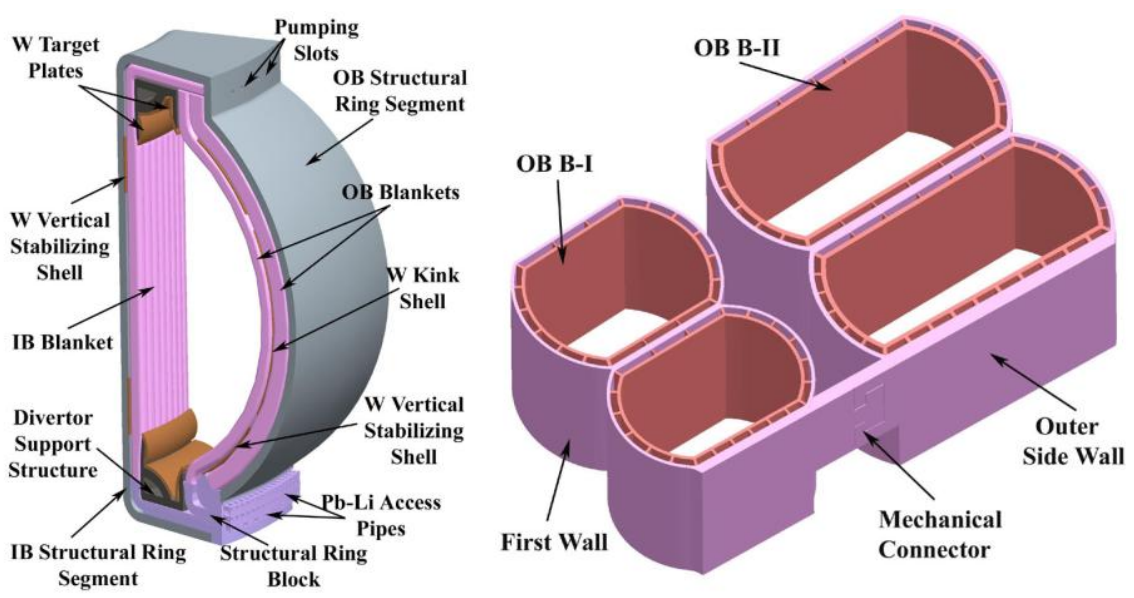

Figure 4. A section of self-cooled lead-lithium blanket, divertors, and structural ring (left) and a section of the outbouard blanket (right) for ARIES-ACT1 fusion power reactor concept [37] (courtesy, The ARIES Team).

Table 1. Operating conditions and design requirements for $\mathrm{SiC} / \mathrm{SiC}$ structures in some of proposed blanket concepts.

\begin{tabular}{|c|c|c|c|}
\hline & \multicolumn{3}{|c|}{$E C P P C S$} \\
\hline & ARIES-ACT1 & & Dream \\
\hline & & Model D & \\
\hline & \multicolumn{3}{|c|}{$S C L L$} \\
\hline Coolant / breeder & $\mathrm{Pb}-\mathrm{Li}$ & $\mathrm{Pb}-\mathrm{Li}$ & $\mathrm{He} / \mathrm{Li}_{2} \mathrm{TiO}_{3}$ \\
\hline Coolant temperature, inlet/outlet $\left({ }^{\circ} \mathrm{C}\right)$ & $740 / 1030$ & $700 / 1100$ & $600 / 900$ \\
\hline Structural material temperature, $\min . / \max .\left({ }^{\circ} \mathrm{C}\right)$ & $740 / 960$ & $700 / 990$ & $600 / 1000$ \\
\hline Max. SiC/coolant interface temperature $\left({ }^{\circ} \mathrm{C}\right)$ & $<960$ & 915 & 900 \\
\hline Fluence lifetime & $3 \%$ burn-up & $\mathrm{N} / \mathrm{S}$ & $\mathrm{N} / \mathrm{S}$ \\
\hline \multirow{2}{*}{ Stress loading (MPa) } & Combined & Normal <109 & FW Tresca \\
\hline & $<190$ & Shear $<57$ & $<60$ \\
\hline Thermal conductivity at operating temperature, & $10\left(600^{\circ} \mathrm{C}\right)$ & \multirow[b]{2}{*}{15} & \multirow[b]{2}{*}{15} \\
\hline transverse $(\mathrm{W} / \mathrm{m}-\mathrm{K})$ & $20\left(1000^{\circ} \mathrm{C}\right)$ & & \\
\hline Thermal expansion coefficient, in-plane ( $\mathrm{ppm} / \mathrm{K})$ & 4 & 4 & 3.3 \\
\hline
\end{tabular}




\subsection{LM blanket FCI}

The main functions of the LM blanket $\mathrm{FCl}$ are to electrically and thermally insulate the reducedactivation ferritic/martensitic steel structures from the flowing liquid metal that is of high temperature and highly conductive. Therefore, the primary requirements to the $\mathrm{FCl}$ materials (or component) are adequately low electrical and thermal conductivities in the throughthickness orientation of the wall. The $\mathrm{FCl}$ is obviously a less demanding application for SiCbased ceramics and composites than the blanket/FW structures, as the key material requirements are summarized in Table 2 . The materials and design requirements have been identified to fair details [45] and several SiC-based FCl concepts including those using the twodimensional (2-D) SiC/SiC [46] and engineered porous SiC structures [47] have been proposed. The previous studies have identified that today's nuclear grade 2-D SiC/SiC composites meet most of the required properties including the thermal and electrical insulating properties and the ability to survive the temperature drop exceeding $200 \mathrm{~K}$ across the thickness [46], whereas the SiC in other forms may provide some benefit-disadvantage trade-offs [47]. The remaining critical issues include the chemical compatibility for the SiC - steel - LLE ternary system in the practical temperature and flow conditions, the potential effects of the aggressive nuclear transmutation during the power reactor operation on various properties (also true for structural applications), and the hermetic joining that withstand both the radiation and the environment. 
Table 2. Operating conditions and design requirements for flow channel inserts for some of the proposed fusion power reactor liquid metal blanket concepts.

\begin{tabular}{lccc}
\hline & US DEMO & ARIES-ACT2 & EC PPCS \\
& DCLL & HCLL & Model C HCLL \\
\hline Coolant / breeder & $\mathrm{He} \& \mathrm{Li}-\mathrm{Pb}$ & $\mathrm{He} / \mathrm{Li}-\mathrm{Pb}$ & $\mathrm{He} / \mathrm{Li}-\mathrm{Pb}$ \\
Max. SiC / breeder interface temperature $\left({ }^{\circ} \mathrm{C}\right)$ & 700 & 640 & 700 \\
Fluence lifetime & $\mathrm{N} / \mathrm{S}$ & $\mathrm{N} / \mathrm{S}$ & $\mathrm{N} / \mathrm{S}$ \\
& Design & & Tensile $<110$ \\
Local stress loading (MPa) & allowable 120 & & Von Mises $<140$ \\
Thermal conductivity, transverse (W/m-K) & $1-5$ & $2($ all temp. $)$ & $2\left(600^{\circ} \mathrm{C}\right)$ \\
Electrical conductivity, transverse (S/m) & $<\sim 20$ & & 4 \\
Additional note & & & Joining assumed \\
Reference & {$[45]$} & N/A & {$[43]$} \\
\hline
\end{tabular}

\section{Recent progress in fusion SiC/SiC R\&D}

In this section, some of the recent progresses in the research and development of SiC ceramics and composite materials technology in fusion or related programs are highlighted. These developments are considered to belong to TRL's 2 (e.g., targeted materials development), 3 (e.g., basic radiation effects and joining technologies), through 4 (e.g., evaluations for designlimiting factors).

\subsection{Joining development and evaluation}

Technology development for joining $\mathrm{SiC} / \mathrm{SiC}$ to itself or other materials is essential for the blanket integration and at least preferred for the $\mathrm{FCl}$ assembling. The requirements for the joints will include the mechanical robustness, tolerance against neutron irradiation, chemical 
stability in the operating environment, and the hermeticity to liquid metal or helium depending on the design. While there have been developed a wide variety of methods for joining SiC to self or various metals, none of them has been developed or designed to operate in nuclear environments. Recently, several candidate SiC joining methods for nuclear applications had been down-selected, optimized for the radiation stability, and evaluated after neutron irradiation up to $\sim 5$ dpa at elevated temperatures in an international collaboration among US, Japan, and Italy [48].

The joining methods evaluated were 1) a diffusion bonding with the titanium insert resulting in a $\mathrm{Ti}_{3} \mathrm{SiC}_{2} / \mathrm{Ti}_{5} \mathrm{Si}_{3}$ in the bonding layer, 2) a displacement reaction bonding with the $\mathrm{TiC} / \mathrm{Si}$ green tape producing a $\mathrm{Ti}_{3} \mathrm{SiC}_{2} / \mathrm{SiC}$ bonding layer, 3) SiC-based transient eutectic-phase (TEP) joining with the mixed oxide additives for bonding with a seamless NITE-like SiC using either a mixed powder slurry or a green tape, and 4) $\mathrm{CaO}-\mathrm{Al}_{2} \mathrm{O}_{3}$ glass-ceramic tailored to produce a fully ceramic $\mathrm{CaO} / \mathrm{Al}_{2} \mathrm{O}_{3} / \mathrm{SiO}_{2}$ bonding layer. The substrate materials that were joined together included the high purity CVD SiC, the NITE-like sintered SiC, and the Tyranno-SA3/NITE SiC composite. After neutron irradiation to $\sim 3$ to $\sim 5 \mathrm{dpa}$ at 500 or $800^{\circ} \mathrm{C}$ in $\mathrm{HFIR}$, all the evaluated joints exhibited no or only slight decrease in the torsional shear failure resistance, demonstrating the encouraging radiation tolerance. At the same time, microcracks were often observed in the non-SiC bonding materials as shown in Figure 5, implying potential hermeticity issues likely arising from the differential swelling between $\mathrm{SiC}$ and the bonding layer. A followup program extending the irradiation temperature range and fluence level is in progress.

One of the difficulties in this irradiation program was the serious lack of commonly used test methods for determination of strength of the ceramic joints in an adequately defined stress state. For this reason, a test method for torsional shear failure resistance of ceramic joint test 
articles was newly developed as a part of the collaboration program. As the result, a test method that determines the failure resistance of the miniaturized ceramic joint specimens in solid or perforated hourglass geometries was successfully established [49], enabling evaluation of the effects of neutron irradiation (and environmental exposure) on the joint strength.
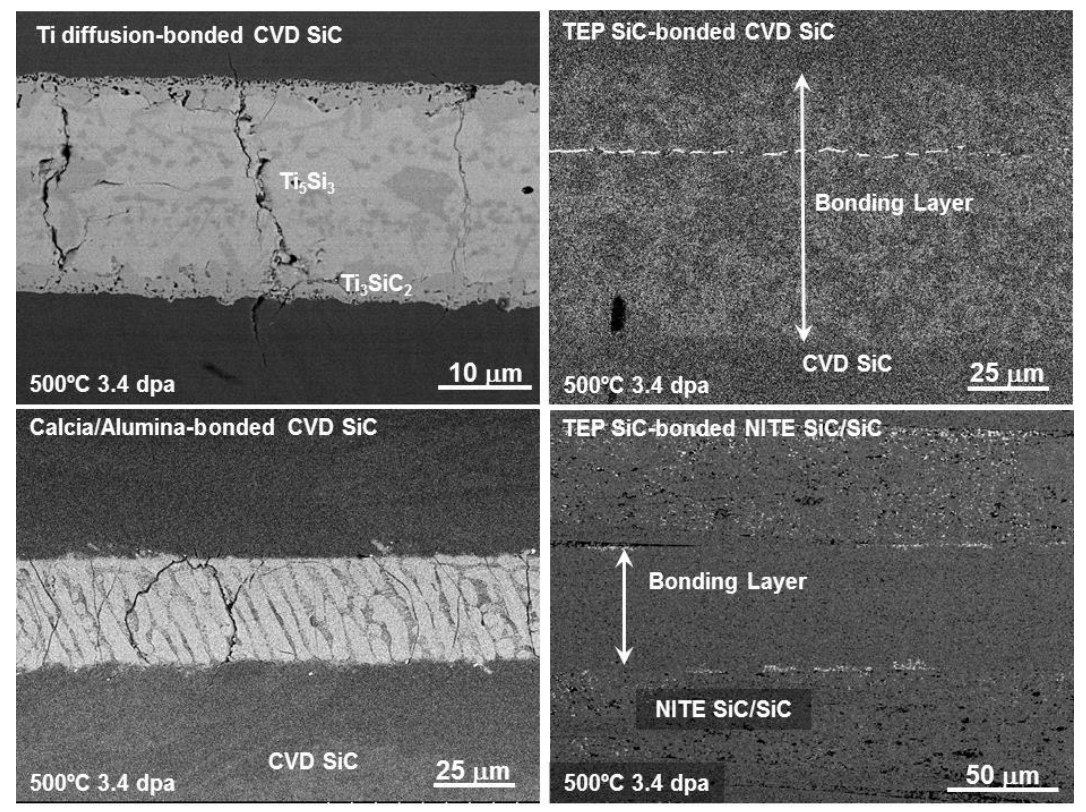

Figure 5. Scanning electron micrographs of some of radiation-tolerant silicon carbide joints after neutron irradiation in High Flux Isotope Reactor.

\subsection{Alternative composites}

The CVI SiC matrix composites with the third generation near-stoichiometric SiC fibers are considered the reference nuclear-grade $\mathrm{SiC} / \mathrm{SiC}$ composites because of the perceived radiation tolerance and the chemical compatibility of the high purity, stoichiometric SiC matrix with various harsh environments. However, performances of the CVI SiC matrix composites involve certain limitations including the relatively low thermal conductivity due to their inherent porosity, the moderate proportional limit stresses for the same reason, and the gas 
permeability due to the process-induced matrix microcracking. Moreover, the current nearstoichiometric SiC fibers and the certain pyrocarbon $(\mathrm{PyC})$ interphases are rather unlikely to take full advantage of the inherent high radiation tolerance of high purity SiC, as elaborated later. Therefore, there will be opportunities for the composite materials made of the alternative fibers, interphases, and/or matrices to complement or replace the today's reference SiC/SiC.

As mentioned earlier, the NITE SiC/SiC composites have demonstrated the stability under neutron irradiation up to intermediate fluence levels [17]. The current efforts in advancing this processing technique in Japan are focused on the manufacture of thin walled, small diameter tubes for the fuel cladding applications [50] and the development of interphase-less porous NITE-like SiC matrix composites toward the reduced cost manufacturing [51].

In the European program, the slip infiltration-based SITE processes were developed as alternative process for matrix densification of $\mathrm{SiC} / \mathrm{SiC}$ composites with 3-dimensional architecture. The process utilizes a combination of two techniques: 1) infiltration of the fabric preform with fine (nano-sized and submicron) SiC particles from aqueous suspension by electrophoretic (infiltration) deposition, EP(I)D, and 2) densification with the aid of a preceramic polymer by the PIP [52]. During the EP(I)D, the porous preform is infiltrated with a large amount of crystalline $\beta$-SiC powder, which serves as a passive filler during the PIP densification steps. In contrast to pressure-assisted infiltration of the fabric with SiC powder, $E P(I) D$ is effective in achieving a homogeneous infiltration through thickness of the preform with a good infiltration of inter- as well as intra-bundle areas. Due to large amount of SiC powder introduced into the fabric, the densification of final material is enhanced and presence of large voids, typical for the conventional PIP process, is avoided. 
Densification of the green composite is achieved by vacuum infiltration of pre-ceramic polymer followed by pyrolysis and crystallization. After six PIP cycles with final thermal treatment at $1600{ }^{\circ} \mathrm{C}, 87 \%$ of density is achieved, the material is composed of highly crystalline $\beta$-SiC, possessing a relatively high thermal conductivity $(65 \mathrm{~W} / \mathrm{m}-\mathrm{K}$ at $\mathrm{RT}$ and $30 \mathrm{~W} / \mathrm{m}-\mathrm{K}$ at $1000 \circ \mathrm{C})$ $[52,53]$, which is partly the consequence of absence of oxide phases and relatively large grain size. In comparison to the standard PIP processing, a more homogeneous matrix with much smaller pores and a similar density is obtained with fewer densification steps [54], as shown in Figure 6. Due to higher maximum temperatures used in the crystallisation step, the SITE matrix exhibits higher crystallinity in comparison to standard PIP processing, where lower temperatures were used in order to achieve densification.
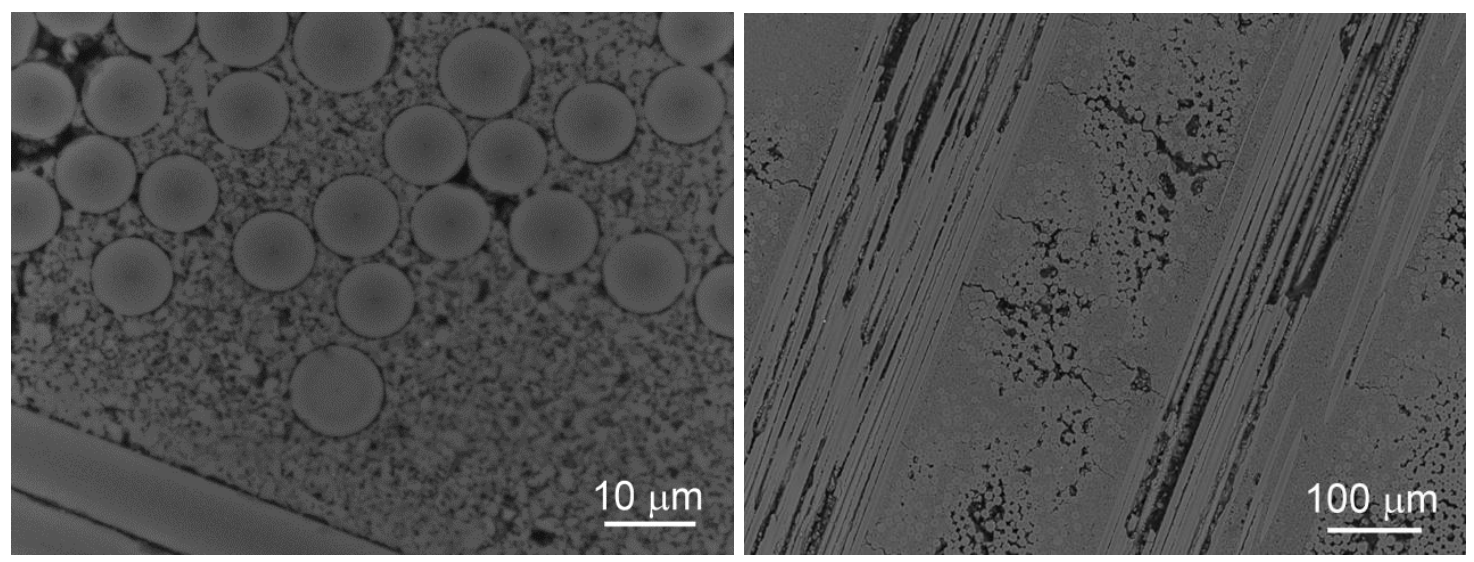

Figure 6. Typical scanning electron microscopy images of a SITE composite at different magnifications.

As the SITE-SiC/SiC composite is composed only of highly crystalline SiC with no sintering additives, it relates to the European target - low -activation material with relatively high thermal conductivity. The main objectives of further work are to improve mechanical strength by using better interphase layer and to apply a W-rich surface layer which will serve as 
impermeable coating and will widen the application area. The SITE process has not been demonstrated beyond a laboratory scale production, but due to the nature of the involved procedures, the process itself has good potential for up-scaling.

\subsection{Chemical compatibility}

Chemical compatibility of the SiC - LLE system in non-static conditions is being studied in the Japan-EU Broader Approach (BA) program, specifically addressing the effects of surface conditions (fiber penetration, oxidation, etc.), coating on fibers, and impurities (e.g., trace elements that exist in irradiated environment and ferritic-martensitic steel-corrosion products). The recent experiment in Japan employing the rotating disc technique indicated the lack of obvious reactions or corrosion at the CVD SiC disc surfaces after an exposure to LLE for $1000 \mathrm{~h}$ at $900^{\circ} \mathrm{C}[55]$.

A thermal convection LLE loop facility has been constructed at Oak Ridge National Laboratory. This new facility enables a critical evaluation of the materials compatibility in an LLE flow environment at a temperature gradient of $\sim 150^{\circ} \mathrm{C}$ while the peak temperature is currently limited at $550^{\circ} \mathrm{C}$, making it suitable for evaluating the $\mathrm{FCl}$ materials for steel-structure LLE blankets. The future plans include gradual increases of the peak temperature as performance data justifies.

\subsection{Electronic properties}

In the BA program, the in-situ volume electrical conductivity measurements were carried out for SiC under various irradiation sources (gamma-ray, X-ray, $14 \mathrm{MeV}$ fusion neutrons) in various atmospheres (air, He and vacuum), in order to understand the radiation effects on electrical 
properties of SiC. The radiation-induced conductivity (RIC), which is an instantaneous increase in the electrical conductivity by electronic excitation, occurred in the beginning of ionizing dose [56]. The RIC values gradually increased with an increase of the dose and subsequently became almost constant. As for the base conductivity in the absence of radiation, the similar radiationinduced phenomenon was observed as the rapid increase at the lower dose of approximately $10 \mathrm{kGy}$ and the gradual increase at the higher dose. Therefore, the dose dependence of RIC was associated with the degradation in base conductivity with dose: radiation-induced electrical degradation (RIED)-like behavior. On the other hand, the RIED-like behavior may be caused by a change of electronic structure due to the electronic excitation essentially, resulting from the covalent nature of SiC. The preliminary XPS results suggest the dissociation of carbon from $\mathrm{SiO}_{x} \mathrm{C}_{3-\mathrm{x}}$ composition existing on the top-most surface. The dependence of dose rate was summarized in Figure 7. It was found that the RIC values for the mono-crystalline $4 \mathrm{H}-\mathrm{SiC}$ and CVD (poly-3C) SiC under X-ray irradiation at room temperature were proportional to the dose rates and 3-4 and 5-6 orders of magnitude higher than those in oxide materials, respectively. Figure 7 also summarizes the temperature dependence of electrical conductivity of various types of SiC materials, indicating that the increasing electrical conductivity at hightemperatures is due primarily to the thermal effect with the impact of RIC negligible. 

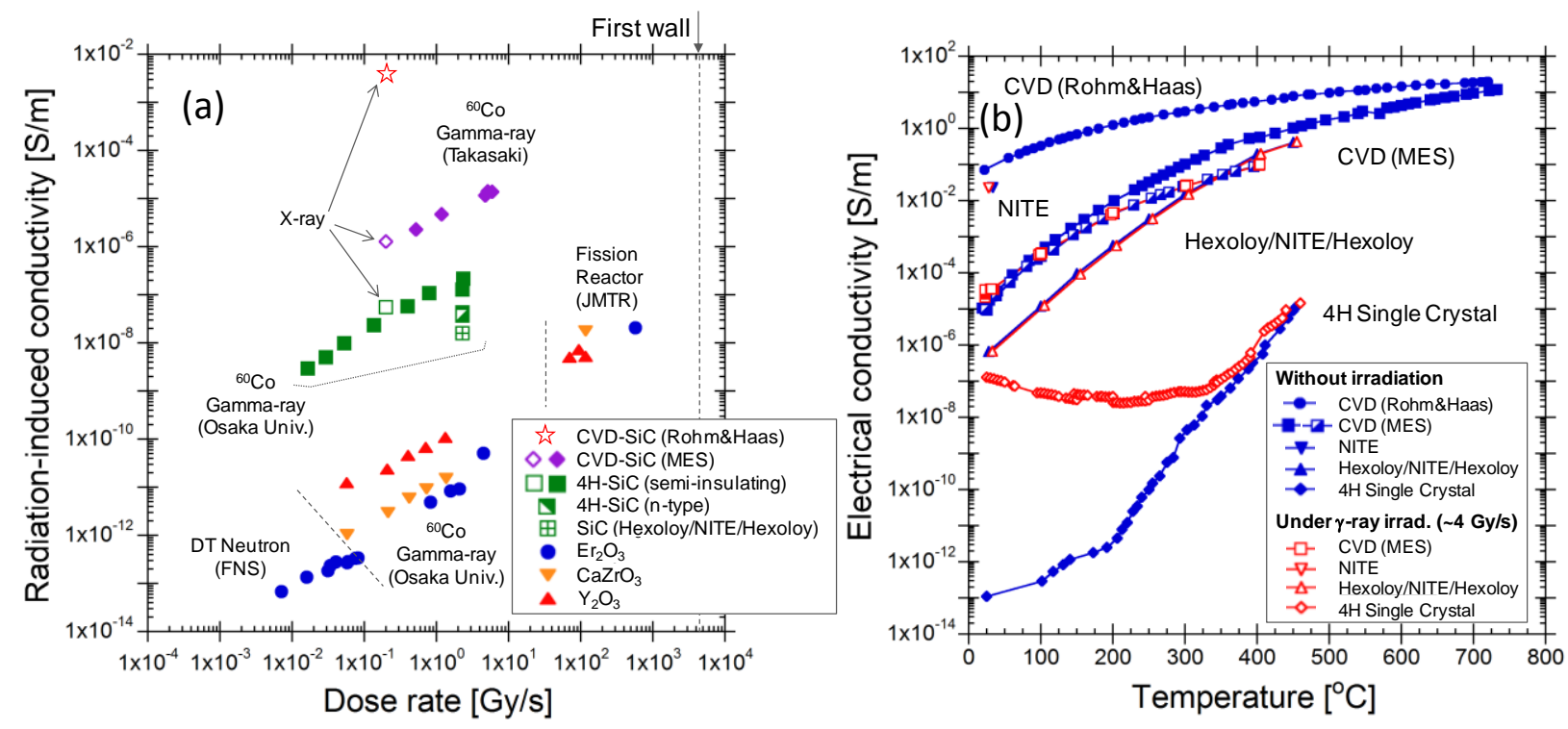

Figure 7. Radiation-induced conductivity of SiC and ceramic oxides: (a) dependence of dose rate [3] and (b) dependence of temperature.

\subsection{Interfacial characterization}

The mechanical properties of the fiber-matrix interfaces are critical in designing and determining the properties of $\mathrm{CMC}^{\prime} \mathrm{s}$ [57]. A novel experimental technique to determine some of the interfacial properties was recently developed in the US fusion program [58]. In this exercise, micro-pillar samples involving the fiber-matrix interfaces at varied slant angles are prepared by the focused ion beam micro-processing followed by the compressive failure load measurements using a nano-indentation device, so that the slant angle dependence of the interfacial shear failure load explicitly gives the cohesive shear debond stress and the internal debond friction coefficient per the Mohr-Coulomb criterion. These data also enables more credible determination of the interfacial sliding stress when combined with conventional techniques such as the single filament push-out method. 


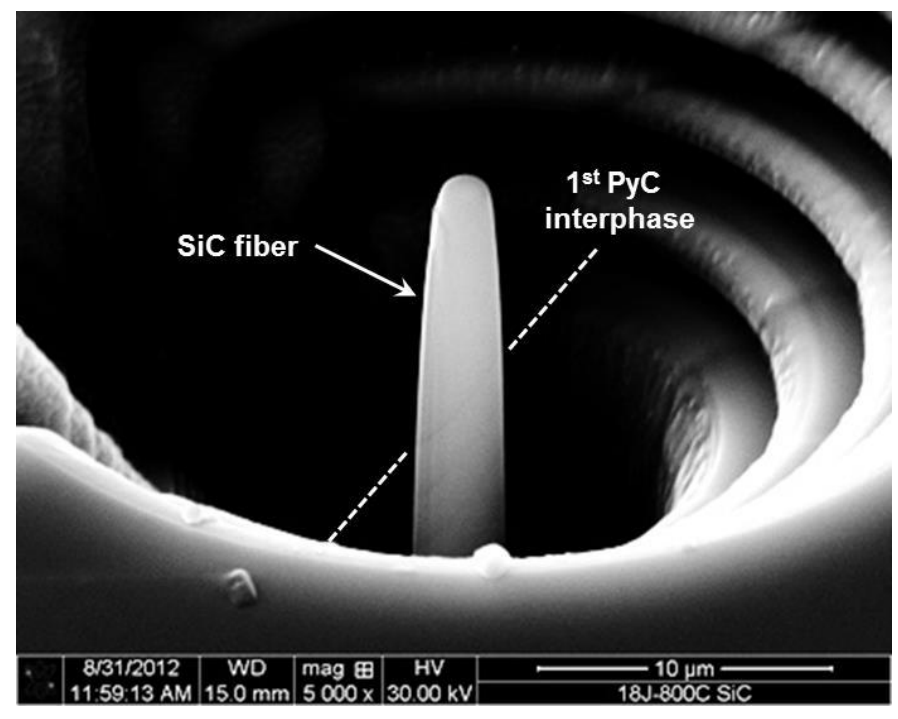

Figure 8. A slant interface micro-pillar prepared for interfacial mechanical properties determination [58].

\subsection{Fundamental radiation effects}

The exceptional radiation stability of $\mathrm{SiC}$ is often attributed to the presence of very high density point defects and clusters, suppressing the net fluxes and the long-range diffusion of migrating point defects, consequently retarding or eliminating the progressive evolutions of various radiation-induced phenomena that are commonly seen for many other materials at elevated temperatures. This self-stabilizing effect in $\mathrm{SiC}$, or the radiation-induced radiation insensitivity, may be visualized in Figure 9, where the estimated effective sink strength in the first order effective medium approach for the radiation-produced matrix defects in SiC is compared to the geometrically estimated sink strengths for engineered ceramic nano-features in some of the advanced radiation-tolerant steels [59]. The sink strength of $10^{16} \mathrm{~m}^{2}$ is considered a rather conservative criterion for the very effective suppression of the migrating defect flux. 


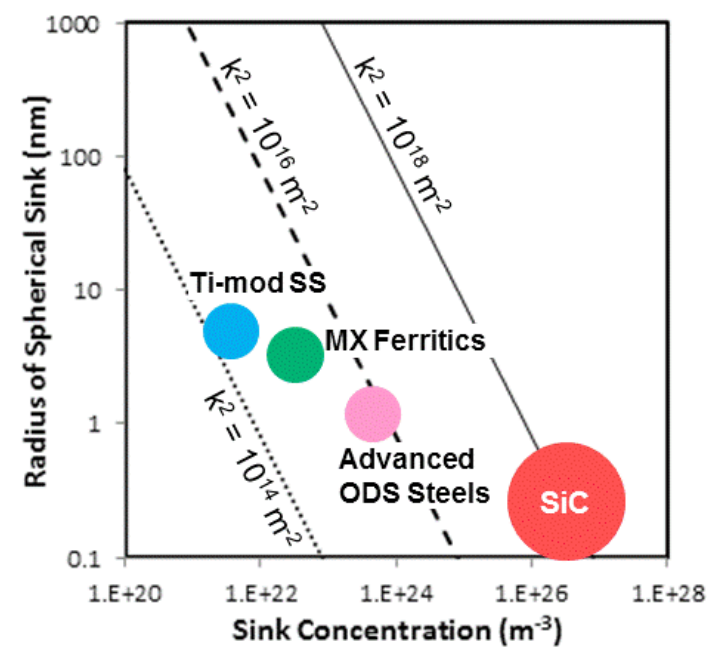

Figure 9. Comparison of estimated equivalent sink strength (SS) of self-defects in irradiated SiC in an intermediate temperature range $\left(\sim 200-\sim 800^{\circ} \mathrm{C}\right)$ with those estimated for engineered dispersants in advanced radiation-tolerant alloys.

While it is convincing that the matrix defects that account for the saturatable swelling for SiC in the intermediate temperature range are very effectively suppressing the migrating defect fluxes, detailed physical processes of the formation of the extremely highly defected matrix that selfstabilizes remain to be explored through both simulations and experiments. Among the interesting results from the recent atomistic simulation on the radiation-induced defect productions and evolutions is the finding of very limited in-cascade recombination in SiC. Samolyuk et al [60] reported that only $\sim 50 \%$ of the Frenkel pairs produced in cascade events annihilate through the in-cascade recombination (Figure 10), in contrast to 99\% typical for bcc iron, in the molecular dynamics (MD) simulation. The outstanding feature at the MD cutoff time is the closely separated vacancy - interstitial pairs that do not recombine for both carbon and silicon sublattices, attributed to the significant recombination barrier for the Frenkel pair recombination. Hu et al. has demonstrated presence of such a high recombination threshold 
energy for the silicon Frankel pair in SiC in a DFT calculation [61], further implying the important role of recombination barrier in the self-stabilization mechanism of SiC.

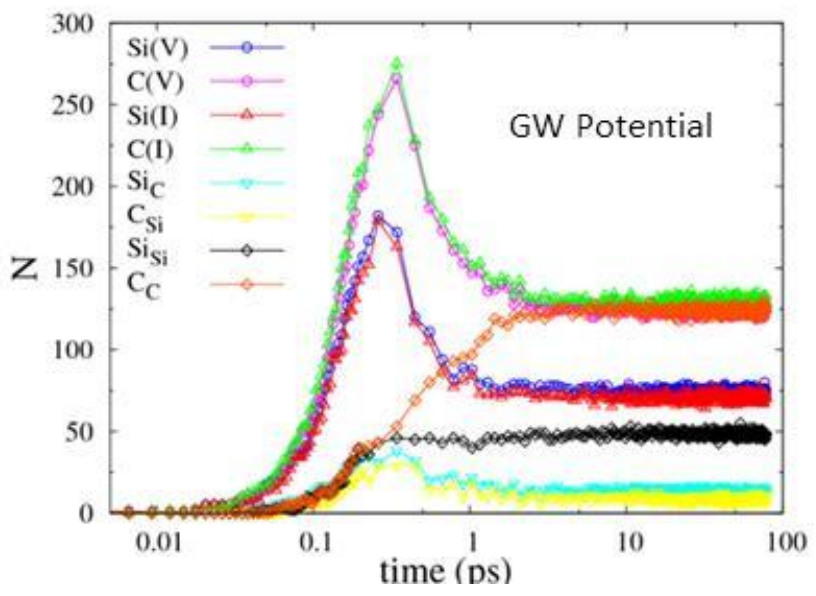

Figure 10. Time evolutions of the numbers of Frenkel defects, antisites, and recombinations during a $10 \mathrm{keV} \mathrm{Si}$ primary knock-on event as calculated by a molecular dynamics model using the Gao-Weber potential [60].

\subsection{High dose irradiation effects}

The recent data from a high dose irradiation of a reference SiC/SiC composite in HFIR presented both promise and limitations [62]. In this experiment, the Hi-Nicalon Type S, CVI SiC matrix composite with the $\mathrm{PyC} / \mathrm{SiC}$ multilayered interphase was irradiated to $71-74 \mathrm{dpa}$ at 300, 500, and $800^{\circ} \mathrm{C}$. The results demonstrated the continued saturations (after the saturation was reached at $<2 \mathrm{dpa}$ ) in swelling, thermal conductivity, and dynamic Young's modulus, implying the lack of progressive radiation effects mainly in the CVI SiC matrix up to these very high fluence levels. The proportional limit stress was retained at the pre-irradiation level after irradiation at $800^{\circ} \mathrm{C}$, confirming the integrity of the matrix. However, the ultimate flexural strength decreased moderately at 500 and $800^{\circ} \mathrm{C}$ and very significantly at $300^{\circ} \mathrm{C}$, with the proportional limit stress somewhat reduced at $500^{\circ} \mathrm{C}$ and significantly reduced at $300^{\circ} \mathrm{C}$. The 
fracture surfaces with some fiber pull-out remain unchanged after irradiation except for the $300^{\circ} \mathrm{C}$ case where both the composite and fiber fracture surfaces appeared unusually flat.

These observations collectively convince one that the Hi-Nicalon Type S fiber deteriorated, more significantly at lower irradiation temperatures, and the interphase compromised its function after the $300^{\circ} \mathrm{C}$ irradiation. The transmission electron microscopy analysis revealed evidences for the significant microstructural modifications around the interphase [62]. The current effort is focusing on identification of the cause for fiber degradation with the radiation instability of the second phases is suspected to be the culprit. Moreover, new irradiation campaigns to determine the high fluence effects on the Tyranno-SA3 and the SCS-Ultra SiC fiber composites have been initiated in the US program.

\subsection{Irradiation creep}

Irradiation creep is an important phenomenon that often contributes to define the design windows for nuclear structural materials. The previous in-pile bend stress relaxation (BSR) creep study by Katoh et al. revealed the linear couplings of the initial transient irradiation creep with the stress magnitude and the transient swelling for various grades CVD SiC [63]. The relatively small coupling coefficients between the creep and swelling strains were determined, denying the possibility of significant creep-enabled mitigation of the swelling-induced stress that develops in temperature-graded and/or flux-graded structures made of SiC-based materials. Such stress is anticipated to dominate in the SiC-based fusion $\mathrm{FCl}$ [45] and the fission fuel clads [32]. A companion study by Koyanagi et al. for the NITE SiC/SiC composite and its matrix material revealed the creep strains that are greater than for CVD SiC and slightly nonlinear in stress dependence, implying the significant contributions from both thermal and 
irradiation creep at the impure grain boundaries [64]. The NITE SiC/SiC composite exhibited the creep behavior close to that for CVD SiC, indicating the decent creep resistance for the TyrannoSA3 fiber.

These earlier low fluence BSR experiments not only revealed the initial transient irradiation creep properties of these materials but proved applicability of the stress relaxation technique to study the irradiation creep behavior at higher fluence levels, because only small fractional relaxations have taken place during the first dpa or two. Based on this a set of BSR experiments were added toward the irradiation to fluences beyond the initial transient creep regime. The first data that were recently made available in the $\sim 10$ dpa range, Figure 11 , likely indicate the slow progression of creep deformation with the ever-decreasing instantaneous creep compliances for the CVD SiC. The lack of any symptom of the onset of steady-state irradiation creep becoming apparent at the $~ 10$ dpa fluence levels adds a unique feature to the irradiation response of $\mathrm{SiC}$. These irradiation creep data will be fully analyzed after completion of the planned irradiation experiments that extend to $30 \mathrm{dpa}$.




Figure 11. Fluence-dependent stress relaxation behavior of CVD SiC during neutron irradiation at $380-1180{ }^{\circ} \mathrm{C}$, showing minor temperature dependence of irradiation creep behavior. Dashed lines are for hypothetical steadystate creep for the constant creep compliance indicated by the labels.

\subsection{Ion irradiation studies}

The irradiation creep behavior of $\mathrm{SiC}$ and the effect of helium on it were recently studied by means of ion irradiation (self-ion and dual-beam with helium) that offers the precise control of the irradiation conditions [65]. The tension surfaces of elastically bent thin specimens were irradiated with $5.1 \mathrm{MeV} \mathrm{Si}^{2+}$ ions up to $3 \mathrm{dpa}$ at various temperatures, which is referred to as a single-ion experiment. Additional $\mathrm{He}^{+}$ions were irradiated simultaneously in the dual-ion experiment to simulate the $(n, \alpha)$ reaction. Results for cases of 150 MPa stress are shown in Fig. $\mathrm{X}$ for both (a) single-ion and (b) dual-ion experiments. Irradiation creep was detected above $400{ }^{\circ} \mathrm{C}$ in the single-ion case, where a linear relationship between irradiation creep and swelling was observed at $400-800^{\circ} \mathrm{C}$ for all stress levels studied. The proportional constant of the linear relationship was strongly dependent on temperature and stress. A rapid reduction in creep strain was observed above $1000^{\circ} \mathrm{C}$, indicating thermal creep is more operative. On the basis of the microstructural analysis in this work, anisotropic distribution of self-interstitial atom (SIA) clusters was suspected to be one of the key creep mechanisms. Some interesting results were obtained from re-irradiation under stress after the irradiation without stress. The creep strain was significantly retarded by pre-irradiation to even $0.01 \mathrm{dpa}$ at 400 and $600^{\circ} \mathrm{C}$. This implies that the loop orientation, and/or the population of other key contributors, was determined very early in the irradiation regime. For the dual-ion cases, irradiation creep was seemed to be absent or very limited at all irradiation temperatures studied $\left(400-800^{\circ} \mathrm{C}\right)$. Although further 
data may be required for determining the helium effects, microstructural analysis indicated that helium inhibited the stable growth of SIA clusters and prevented them from exhibiting anisotropic distribution.
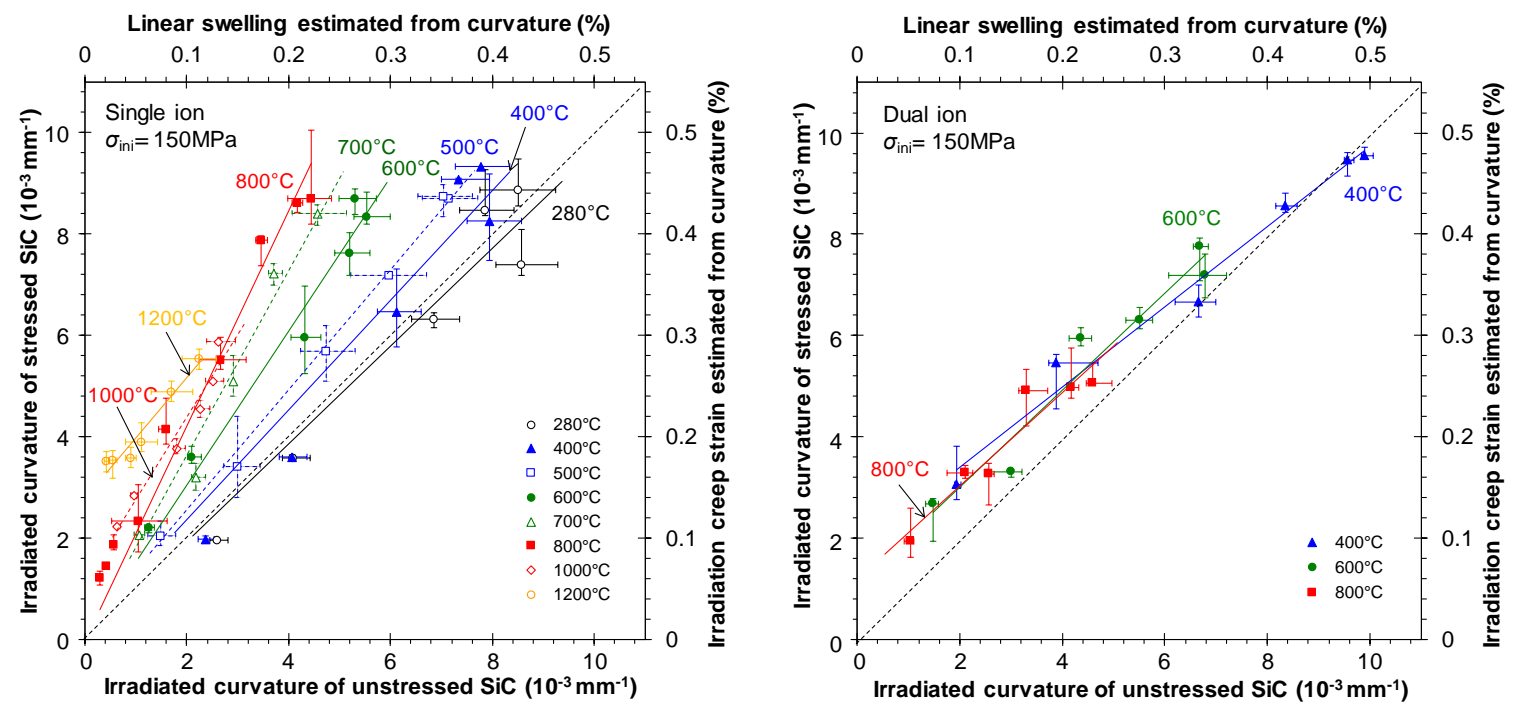

Figure 12. Relationship between the irradiated curvatures of stressed and unstressed specimens at various irradiation temperatures in (a) single ion and (b) dual ion experiments. The radii of irradiated samples were measured at room temperature using the AFM after samples were released from the straight or curved fixtures. [65]

\subsection{Thermal conductivity modeling}

Recent progress in $\mathrm{SiC} / \mathrm{SiC}$ thermal conductivity modeling [66] explores the analogy between the variables used in elasticity and those in steady-state heat conduction established by Hatta and Taya [67]. This analogy allows the use of the formulation established for the elastic stiffness of a unidirectional (UD) composite using the Eshelby equivalent inclusion method to obtain the expression for the composite thermal conductivity. To date, the Eshelby's equivalent inclusion 
method [68] combined with a Mori-Tanaka type model [69] presents one of the most efficient and accurate approaches for the prediction of the composite elastic properties [70]. To fully exploit this analogy, a Mori-Tanaka type model combined with the Eshelby's equivalent inclusion method has been explored to predict the thermal conductivities of these composites as a function of temperature and the constituent parameters such as thermal properties of the fiber and matrix phases, fiber volume fraction, fiber orientation, and fiber/matrix interfacial thermal conductance [67-70]. A computational tool named EMTA (Eshelby-Mori-Tanaka approach) was developed to implement the EMTA models for the computation of thermal conductivities of fiber-reinforced composites [71].

Based on the EMTA method that successfully modeled the thermal conductivities of 2-D woven Hi-Nicalon Type-S CVI SiC/SiC [72], a more fundamental approach has been developed for predicting the thermal conductivities of the composites subjected to neutron irradiation in the point defect swelling regime. The effects of grain size and temperature were incorporated into computations for CVD-SiC to compute the thermal conductivity of unirradiated SiC constituents with high accuracy. Molecular dynamics (MD) data is used from simulations performed to compute the thermal defect resistance as a function of vacancy concentration in perfect crystal $\beta$-SiC via the Green-Kubo or non-equilibrium MD (NEMD) methods [73]. The computed defect thermal resistances as functions of vacancy concentration (atomic fraction) and irradiation dose are then used to compute the thermal conductivities of polycrystalline SiC including CVD-SiC, nearly stoichiometric SiC fibers, and the ICVI-SiC matrix. Finally, the computed fiber and ICVI-SiC matrix thermal conductivities are used by EMTA, together with a pyrocarbon (PyC) interphase, to compute the thermal conductivities of 2D woven $\mathrm{SiC} / \mathrm{SiC}$ composites subjected to neutron irradiation within the same irradiation dose range corresponding to the point defect swelling 
regime. The predicted thermal conductivity results for irradiated 2D Tyranno-SA/ICVI-SiC and Hi-Nicalon-Type S/ICVI-SiC composites are compared with the available experimental data for similar composites ICVI-processed with these fibers.

Figure 13 shows the transverse thermal conductivities predicted for the two composites as a function of temperature and damage dose ( $d p a)$ using only the experimental thermal resistance data as a function of dose from [74]. This simulation result demonstrates the full power of this approach in being able to separate out the fiber and thermal effects. The beneficial effect of operating at $1073 \mathrm{~K}$ for $\mathrm{SiC} / \mathrm{SiC}$ composites is clearly seen in this prediction. Physically, this is due to the close-pair recombination that results from the elevated temperature radiation damage and this data corresponds to MD results qualitatively.

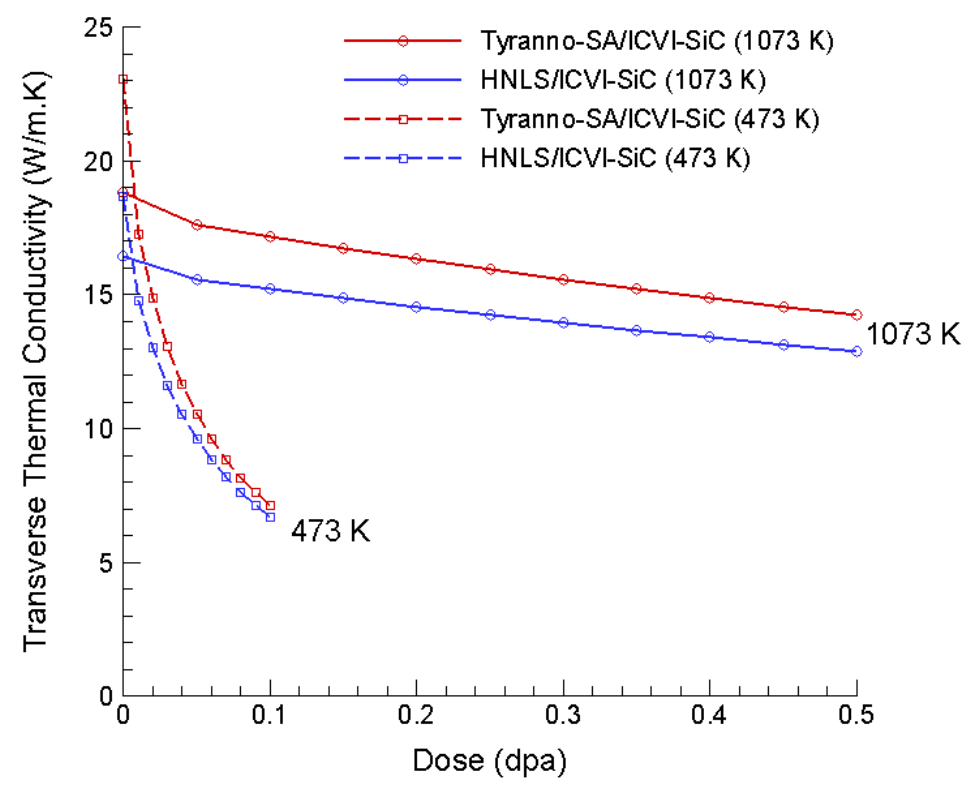

Figure 13. Transverse thermal conductivity vs. dose predicted for the 2D Tyranno-SA/ICVI-SiC and Hi-Nicalon Type-S/ICVI-SiC composites irradiated at $473 \mathrm{~K}$ and $1073 \mathrm{~K}$. 


\subsection{Transmutation effects}

The nuclear transmutations induced by the fusion spectrum neutron irradiation are considered to be the most critical unknown among the key service life-limiting factors for SiC ceramics and composites. The latest neutronics work by Sawan et al.[75] predicts the production rates of 50

- 180 appm He/dpa and $20-70$ appm H/dpa for gaseous transmutations and $10-45$ appm $\mathrm{Mg} / \mathrm{dpa}, 5$ - 18 appm Be/dpa, 3 - 14 appm Al/dpa, and 0.2 - 1.5 appm P/dpa, depending on the blanket concept and magnetic or inertial confinement, for the most notable solid transmutations. The high production rate for helium is known to cause enhanced swelling due like to stability of the interstitial helium [76] at intermediate temperatures during ion irradiation [77] and through stabilization of vacancy clusters at high temperatures $\left(>^{\sim} 1000^{\circ} \mathrm{C}\right)$ during ion [78] and neutron irradiation [79]. The recent triple-ion irradiation study implies the minor effects of hydrogen implantation in addition to helium on the irradiated microstructural evolutions [80].

The implications of the significant solid transmutations are largely unknown. Aluminum is known to alter the oxygen transport in $\mathrm{SiC}$ at high temperatures making its burn-in a significant concern in terms of corrosion resistance [75]. Moreover, most of the burn-in elements will modify the electronic properties of SiC as an impurity semiconductor. In lack of an intense fusion neutron source today, the ion implantation and the atomistic simulations are useful tools for exploring the solid transmutation effects [81]. The recent theoretical study by Hu et al. employing the density functional theory indicates significant $\mathrm{Mg}$ mobility and that $\mathrm{Mg}$ clustering is energetically favored with end result forming $\mathrm{Mg}_{2} \mathrm{Si}$ [61]. Further theoretical and experimental investigations into the Mg burn-in are in progress in the US fusion materials program. 


\section{Conclusions and path-forward}

As reviewed earlier, the nuclear-grade $\mathrm{SiC} / \mathrm{SiC}$ composites are currently establishing a position as a new class of materials that bring in revolutionary high temperature capability, accident tolerance, and radiation tolerance to today's fission energy systems such as the LWR's and HTGR's. In particular, the ASME design code development for CMC core components for high temperature reactors and the associated ASTM standards development will pave a way for qualification of critical nuclear components that are manufactured with these engineered brittle-matrix damage-tolerant composite materials. The long-range development of the accident-tolerant SiC/SiC-based fission fuel clad technology presents an important leverage with fusion structural $\mathrm{SiC} / \mathrm{SiC}$ research because of the challenging requirement for gas tightness under a significant stress loading for both applications. Moreover, the ongoing development and deployment of CMC's in passenger transportation systems present synergy in terms of both the risk management for the critical safety components and operations in extreme high temperature conditions.

Despite the favorable environments for the $\mathrm{CMC}$ research and development in fission and nonnuclear application areas, the international fusion materials programs are up to overcome the significant roadblocks and address various design-limiting factors toward establishing more credible fusion blanket (and possibly PFC) designs with the SiC/SiC components. The critical research areas toward narrowing the technology gaps, or advancing the TRL's, include the high fluence radiation effects on the current and developmental composite materials, robust integration technologies that withstand the harsh operating conditions, chemical compatibility with and tightness against permeation of gaseous or liquid coolant and/or breeding materials, and the effects of gaseous and solid transmutations on a whole range of properties. Moreover, 
advancing the basic understandings of the foundations for the design-limiting phenomena, including the physical processes of radiation damage and the constitutive theories for physical, thermal, mechanical, and fracture properties, are essential.

\section{Acknowledgement}

The authors acknowledge helpful input from and discussion with M. Tillack, K. Terrani, M.

Ferraris, A.G. Perez-Bergquist, K. Leonard, S. Kondo, T. Koyanagi, K. Yueh, K. Ozawa, B. Tsuchiya, T. Shikama, G. Samolyuk, R.E. Stoller, B.N. Nguyen, and S.T. Gonczy. Preparation of this manuscript was supported by Office of Fusion Energy Sciences, U.S. Department of Energy under contract DE-C05-00OR22725 with UT-Battelle, LLC. 


\section{References}

[1] R.J. Price, Effects of fast-neutron irradiation on pyrolytic silicon carbide, Journal of Nuclear Materials, 33 (1969) 17-22.

[2] C.H. Carter, Jr., R.F. Davis, J. Bentley, Kinetics and mechanisms of high-temperature creep in silicon carbide: II, chemically vapor deposited, Journal of the American Ceramic Society, 67 (1984) 732-740.

[3] E.A. Gulbransen, S.A. Jansson, The High-Temperature Oxidation, Reduction, and Volatilization Reactions of Silicon and Silicon Carbide, Oxidation of Metals, 4 (1972) 181-201.

[4] R.J. Price, Properties of silicon carbide for nuclear fuel particle coatings, Nuclear Technology, 35 (1977) 320-336.

[5] L.L. Snead, T. Nozawa, Y. Katoh, T.S. Byun, S. Kondo, D.A. Petti, Handbook on SiC Properties for Fuel Performance Modeling, Journal of Nuclear Materials, 371 (2007) 329-377.

[6] S. Yajima, J. Hayashi, Development of a silicon carbide fibre with high tensile strength, Nature, 261 (1976) 683-685.

[7] R. Naslain, J.Y. Rossignol, P. Hagenmuller, F. Christin, L. Heraud, J.J. Choury, Synthesis and properties of new composite materials for high temperature applications based on carbon fibers and C-SiC or C-TiC hybrid matrices, Revue Chimie Minerale, 18 (1981) 544-564.

[8] W.B. Hillig, Melt Infiltration Approach to Ceramic Matrix Composites, Journal of the American Ceramic Society, 71 (1988) c96-99.

[9] L.V. Interrente, C.W. Whitmarsh, W. Sherwood, Fabrication fo SiC matrix composites using a liquid polycarbosilane as the matrix source, Ceramic Transactions, 58 (1995) 111-118. 
[10] Y. Katoh, S.M. Dong, A. Kohyama, Thermo-mechanical properties and microstructure of silicon carbide composites fabricated by nano-infiltrated transient eutectoid process, Fusion Engineering and Design, 61-2 (2002) 723-731.

[11] R.E. Riley, T.C. Wallace, J.M. Dickinson, Composite Materials for Tokamak Wall Armor, Limiters, and Beam Dump Applications, Journal of Nuclear Materials, $85 \& 86$ (1979) 221-224.

[12] T. Noda, M. Fujita, H. Araki, A. Kohyama, Effect of nuclear data and impurities on the evaluation of induced activity of CVI SiCf/SiC composites, Fusion Engineering and Design, 61-62 (2002) 711-716.

[13] A.R. Bunsell, A. Piant, A review of the development of three generations of small diameter silicon carbide fibres, Journal of Materials Science, 41 (2006) 823-839.

[14] L.L. Snead, E. Lara-Curzio, Interphase integrity of neutron irradiated SiC composites, Materials Research Society Symposium Proceedings, 540 (1999) 273-278.

[15] L.L. Snead, Y. Katoh, A. Kohyama, J.L. Bailey, N.L. Vaughn, R.A. Lowden, Evaluation of neutron irradiated near-stoichiometric silicon carbide fiber composites, Journal of Nuclear Materials, 283 (2000) 551-555.

[16] Y. Katoh, K. Ozawa, C. Shih, T. Nozawa, R.J. Shinavski, A. Hasegawa, L.L. Snead, Continuous SiC Fiber, CVI SiC Matrix Composites for Nuclear Applications: Properties and Irradiation Effects, Journal of Nuclear Materials, (2013) in press.

[17] T. Koyanagi, K. Ozawa, T. Hinoki, K. Shimoda, Y. Katoh, Effects of neutron irradiation on mechanical properties of silicon carbide composites fabricated by nano-infiltrated transient eutectic process, Journal of Nuclear Materials, (accepted in October 2013). 
[18] Y. Katoh, T. Nozawa, A.M. Williams, T. Cheng, P. Dou, L.L. Snead, Properties of Hi-Nicalon Type-S CVI SiC Composite Irradiated to 70 dpa at Elevated Temperatures, ORNL/TM-2012/459, in, Oak Ridge National Laboratory, 2012.

[19] J.C. Mankins, Technology Readiness Assessments: A Retrospective, Acta Astronautica, 65 (2009) 1216-1223.

[20] M.S. Tillack, Readiness levels as applied to selected materials for applications, in: 15th International Conference on Fusion Reactor Materials, Charleston, South Calorina, 2011.

[21] L.L. Snead, Y. Katoh, W.E. Windes, R.J. Shinavski, T.D. Burchell, Ceramic composites for near term reactor application, in: The 4th International Topical Meeting on High Temperature Reactor Technology (HTR-2008), ASME, Washington, D.C., 2008.

[22] Y. Katoh, L.L. Snead, I. Szlufarska, W.J. Weber, Radiation Effects in SiC for Nuclear Structural Applications, Current Opinion in Solid State \& Materials Science, 16 (2012) 143-152.

[23] Y. Katoh, L.L. Snead, T.D. Burchell, W.E. Windes, Composite Materials for High Temperature Reactors: Technology Development Roadmap, in: 5th International Conference on High Temperature Reactor Technology, Prague, 2010.

[24] S.T. Gonczy, New ASTM Committee C28 Material Specifications for Carbon-Carbon and SiCSiC Composite for Nuclear Applications, in: 37th International Conference on Advanced Ceramics and Composites, Daytona Beach, 2013.

[25] M. Konomura, T. Mizuno, T. Saigusa, Y. Ohkubo, A Promising Gas-Cooled Fast Reactor Concept and Its R\&D Plan, in: GLOBAL 2003, New Orleans, 2003.

[26] L. Chaffron, J.-L. Se'ran, Innovative SiCf/SiC Composite Materials for Fast Reactor Applications, Transactions of the American Nuclear Society, 102 (2010) 905. 
[27] C.W. Forsberg, P.F. Peterson, R.A. Kochendarfer, Design options for the advanced hightemperature reactor, in: International Conference on Advances in Nuclear Power Plants, ICAPP 2008, 2008, pp. 733-749.

[28] C. Lorrette, C. Sauder, L. Chaffron, Progress in Developing SiC/SiC Composite Materials for Advanced Nuclear Reactors, in: 18th International Conference on Composite Materials, Jeju, Korea, 2011.

[29] K. Yueh, D. Carpenter, H. Feinroth, Clad in Clay, Nuclear Engineering International, (2010) 14-16.

[30] L.L. Snead, Y. Katoh, K.A. Terrani, An Overview of SiC-Based Fuel and Cladding Technologies in Support of Accident Tolerant Fuel Development, in, EHPG13, 2013.

[31] K.A. Terrani, L.L. Snead, J.C. Gehin, Microencapsulated fuel technology for commercial light water and advanced reactor application, Journal of Nuclear Materials, 427 (2012) 209-224.

[32] M. Ben-Belgacem, V. Richet, K.A. Terrani, Y. Katoh, L.L. Snead, Thermo-mechanical analysis of LWR SiC/SiC composite cladding, Journal of Nuclear Materials, (Accepted for publication). [33] R. Naslain, Design, preparation and properties of non-oxide CMCs for application in engines and nuclear reactors: an overview, Composites Science and Technology, 64 (2004) 155-170. [34] H. Kishimoto, T. Shibayama, T. Abe, K. Shimoda, S. Kawamura, A. Kohyama, Diffusion Bonding Technology of Tungsten and SiC/SiC Composites for Nuclear Applications, IOP Conference Series: Materials Science and Engineering, 18 (2011) 162015.

[35] S.J. Zinkle, N.M. Ghoniem, Operating temperature windows for fusion reactor structural materials, Fusion Engineering and Design, 51-52 (2000) 55-71. 
[36] L.L. Snead, T. Nozawa, M. Ferraris, Y. Katoh, R. Shinavski, M. Sawan, Silicon carbide composites as fusion power reactor structural materials Journal of Nuclear Materials, 417 (2011) 330-339.

[37] X.R. Wang, M.S. Tillack, S. Malang, F. Najmabadi, t.A. Team, Overall power core configuration and system integration for ARIES-ACT1 fusion power plant, Fusion Science and Technology, 64 (2013) 455-459.

[38] A.R. Raffray, L. El-Guevaly, S. Gordeev, S. Malang, E. Mogahed, F. Najmabadi, I. Sviatoslavsky, D.-K. Sze, M.S. Tillack, X. Wang, A. Team, High performance blanket for ARIES-AT power plant, Fusion Engineering and Design, 58-59 (2001) 549-553.

[39] B.A. Pint, J.L. Moser, P.F. Tortorelli, Investigation of Pb-Li compatibility issues for the dual coolant blanket concept, Journal of Nuclear Materials, 367-370 (2007) 1150-1154.

[40] C.I. Contescu, Initial Assessment of Environmental Effects on SiC/SiC composites in Heliumcooled Nuclear Systems, ORNL/TM-2013/319, in, Oak Ridge National Laboratory, 2013. [41] L. Charpentier, M. Balat-Pichelin, H. Glenat, E. Beche, E. Laborde, F. Audubert, High temperature oxidation of SiC under helium with low-pressure oxygen. Part 2: CVD beta-SiC, Journal of the European Ceramic Society, 30 (2010) 2661-2670.

[42] H. Katsui, A. Hasegawa, Y. Katoh, Y. Hatano, T. Tanaka, S. Nogami, T. Hinoki, T. Shikama, Study on Compatibility between Silicon Carbide and Solid Breeding Materials Irradiated under Neutron Irradiation, Fusion Science and Technology, 60 (2011) 288-291.

[43] D. Maisonnier, I. Cook, P. Sardain, R. Andreani, L. Di Pace, R. Forrest, L. Giancarli, S. Hermsmeyer, P. Norajitra, N. Taylor, D. Ward, A conceptual study of commercial fusion power plants, in, European Fusion Development Agreement, 2005. 
[44] S. Nishio, S. Ueda, I. Aoki, R. Kurihara, T. Kuroda, H. Miura, T. Kunugi, Y. Seki, T. Nagashima, M. Ohta, J. Adachi, S. Yamazaki, I. Kawaguchi, T. Hashimoto, K. Shinya, Y. Murakami, H. Takase, T. Nakamura, Improved tokamak concept focusing on easy maintenance, Fusion Engineering and Design, 41 (1998) 357-364.

[45] N.B. Morley, Y. Katoh, S. Malang, B.A. Pint, A.R. Raffray, S. Sharafat, S. Smolentsev, G.E. Youngblood, Recent US research and development for the dual coolant blanket concept, Fusion Engineering and Design, 83 (2008) 920-927.

[46] Y. Katoh, L.L. Snead, C. Shih, R.J. Shinavski, S. Sharafat, S. Smolentsev, T. Nozawa, K. Ozawa, Continuous Fiber Silicon Carbide Composites for Fusion Blanket Flow Channel Insert, in: 20th Topical Meeting on the Technology of Fusion Energy, American Nuclear Society, Nashville, Tennessee, 2012.

[47] S. Sharafat, A. Aoyama, N. Morley, S. Smolentsev, Y. Katoh, B. Williams, N. Ghoniem, Development Status of a SiC-Foam Based Flow Channel Insert for a U.S.-ITER DCLL TBM, Fusion Science and Technology, 56 (2009) 883-891.

[48] Y. Katoh, L.L. Snead, C. Shih, T. Hinoki, T. Koyanagi, T. Toyoshima, M. Ferraris, A. Ventrella, C.H. Henagar, Radiation-Tolerant Joining Technologies for Silicon Carbide Ceramics and Composites, Journal of Nuclear Materials, (Accepted in October 2013).

[49] M. Ferraris, M. Salvo, S. Rizzo, V. Casalegno, S. Han, A. Ventrella, T. Hinoki, Y. Katoh, Torsional Shear Strength of Silicon Carbide Components Pressurelessly Joined by a GlassCeramic, International Journal of Applied Ceramic Technology, 9 (2012) 786-794.

[50] N. Nakazato, H. Kishimoto, Y. Kohno, A. Kohyama, SiC/SiC fuel cladding by NITE process for innovative LWR - cladding forming process development, Ceramic Transactions, 246 (Accepted for publication). 
[51] T. Hinoki, K. Shimoda, Porous Silicon Carbide Composites for LWR Cladding, Transactions of the American Nuclear Society, 106 (2012) 1335-1336.

[52] S. Novak, A. Ivekovic, Fabrication of SiCf/SiC composites by SITE-P process, Journal of Nuclear Materials, 427 (2012) 110-115.

[53] A. Iveković, S. Novak, G. Dražić, D. Blagoeva, S.G. de Vicente, Current status and prospects of SiCf/SiC for fusion structural applications, Journal of the European Ceramic Society, 33 (2013) 1577-1589.

[54] A. Iveković, G. Dražić, S. Novak, Densification of a SiC-matrix by electrophoretic deposition and polymer infiltration and pyrolysis process, Journal of the European Ceramic Society, 31 (2011) 833-840.

[55] C. Park, R. Kasada, S. Konishi, Compatibility of SiC with liquid Pb-Li metal using rotating disc equipment, (To be submitted).

[56] B. Tsuchiya, T. Shikama, S. Nagata, K. Saito, S. Yamamoto, S. Ohnishi, T. Nozawa, Radiation induced changes in electrical conductivity of chemical vapor deposited silicon carbides under fast neutron and gamma-ray irradiations, Fusion Engineering and Design, 86 (2011) 2487-2490. [57] A.G. Evans, D.B. Marshall, The mechanical behavior of ceramic matrix composites, Acta Metallurgica, 37 (1989) 2567-2583.

[58] C. Shih, Y. Katoh, K.J. Leonard, H. Bei, E. Lara-Curzio, Determination of Interfacial Mechanical Properties of Ceramic Composites by the Compression of Micro-pillar Test Specimens, Journal of Materials Science, 48 (2013) 5219-5224.

[59] A.D. Brailsford, R. Bullough, The rate theory of swelling due to void growth in irradiated metals, Journal of Nuclear Materials, 44 (1972) 121-135. 
[60] G.D. Samolyuk, Y.N. Osetskiy, R.E. Stoller, Molecular Dynamics Modeling of Atomic Displacement Cascades in 3C-SiC, in: 16th International Conference on Fusion Reactor Materials, Beijing, 2013.

[61] S. Hu, W. Jiang, W. Setyawan, Y. Wang, C.H. Henager, Jr., R.J. Kurtz, Effects of Si Transmutation to Mg in SiC: A Combined Experimental and Computational Study, in: 16th International Conference on Fusion Reactor Materials, Beijing, 2013.

[62] A.G. Perez-Bergquist, T. Nozawa, C. Shih, K.J. Leonard, L.L. Snead, Y. Katoh, Microstructural Evolution of Advanced Silicon Carbide Composites Neutron-Irradiated to High Fluences, Journal of Nuclear Materials, (to be submitted).

[63] Y. Katoh, L.L. Snead, C.M. Parish, T. Hinoki, Observation and Possible Mechanism of Irradiation Induced Creep in Ceramics, Journal of Nuclear Materials, 434 (2013) 141-151. [64] T. Koyanagi, K. Shimoda, S. Kondo, T. Hinoki, Y. Katoh, Irradiation creep of nano-powder sintered silicon carbide at low neutron fluences, Journal of Nuclear Materials, (Submitted). [65] S. Kondo, T. Koyanagi, T. Hinoki, Irradiation creep of 3C-SiC and microstructural understanding of the underlying mechanisms, Journal of Nuclear Materials, (Accepted). [66] C.H. Henager, Jr., B.N. Nguyen, R.J. Kurtz, Computing Thermal Conductivity of SiC/SiC Composites Including Interfacial and Radiation Damage Effects, in: 16th International Conference on Fusion Reactor Materials, Beijing, 2013.

[67] H. Hatta, M. Taya, Equivalent inclusion method for steady state heat conduction in composites, International Journal of Engineering Science, 24 (1986) 1159-1172.

[68] J.D. Eshelby, The Determination of the Elastic Field of an Ellipsoidal Inclusion and Related Problems, Proceedings of the Royal Society London, A241 (1957) 376-396. 
[69] T. Mori, K. Tanaka, Average stress in matrix and average elastic energy of materials with misfitting inclusions, Acta Metallurgica, 21 (1973) 571-574.

[70] Y. Benveniste, A New Approach to the Application of Mori-Tanaka's Theory in Composite Materials, Mech. Mater., 6 (1987) 147-157.

[71] B.N. Nguyen, EMTA User's Guide, in, Pacific Northwest National Laboratory, Richland, WA, 2010.

[72] B.N. Nguyen, C.H. Henager Jr, Fiber/matrix interfacial thermal conductance effect on the thermal conductivity of SiC/SiC composites, J. Nucl. Mater., 440 (2013) 11-20.

[73] J.-P. Crocombette, G. Dumazer, N.Q. Hoang, F. Gao, W.J. Weber, Molecular dynamics modeling of the thermal conductivity of irradiated SiC as a function of cascade overlap, Journal of Applied Physics, 101 (2007).

[74] L.L. Snead, T. Nozawa, Y. Katoh, T.-S. Byun, S. Kondo, D.A. Petti, Handbook of SiC properties for fuel performance modeling, J. Nucl. Mater., 371 (2007) 329-377.

[75] M. Sawan, Y. Katoh, L.L. Snead, Transmutation of Silicon Carbide in Fusion Nuclear Environment, Journal of Nuclear Materials, 442 (2013) S370-S375.

[76] R.M. Van Ginhoven, A. Chartier, C. Meis, W.J. Weber, L.R. Corrales, Theoretical study of helium insertion and diffusion in 3C-SiC, Journal of Nuclear Materials, 348 (2006) 51-59.

[77] H. Kishimoto, K. Ozawa, S. Kondo, A. Kohyama, Effects of dual-ion irradiation on the swelling of SiC/SiC composites, Materials Transactions, 46 (2005) 1923-1927.

[78] S. Kondo, T. Hinoki, A. Kohyama, Synergistic effects of heavy ion and heliium irradiation on microstructural and dimensional change in b-SiC, Materials Transactions, 46 (2005) 1923-1927. 
[79] T. Hinoki, Y. Katoh, S.M. Gonzales de Vicente, T. Nozawa, L.L. Snead, M. Ferraris, M.E.

Sawan, A. Hasegawa, S. Novak, Current Status of Nuclear Grade Silicon Carbide Composites, in: 15th International Conference on Fusion Reactor Materials, Charleston, South Calorina, 2011.

[80] K. Ozawa, T. Nozawa, H. Uto, Y. Someya, H. Tanigawa, K. Tobita, Swelling of SiC materials and its helium effects for expected operating conditions based on some blanket design using SiC materials, in: 11th International Symposium on Fusion Nuclear Technology, Barcelona, 2013.

[81] Y. Katoh, L.L. Snead, C.H. Henager Jr., A. Hasegawa, A. Kohyama, B. Riccardi, J.B.J.

Hegeman, Current status and critical issues for development of SiC composites for fusion applications, Journal of Nuclear Materials, 367 (2007) 659-671. 